\title{
Income Inequality: The Consequences of Skill-upgrading When Firms Have Hierarchical Organizational Structures
}

\author{
Anders Frederiksen* ${ }^{*}$ Odile Poulsen ${ }^{\dagger}$
}

July 3,2015

\begin{abstract}
During the last three decades, most developed countries have experienced increasing income inequality. Using Danish register data from 1992 to 2007 for all private-sector employees, we confirm that income inequality has increased in Denmark. We also observe an increase in the relative employment of highly-educated individuals, as well as differential income growth rates across employee subgroups where, in particular, managers experienced significant real income progression. We use an equilibrium search framework with on-the-job search to derive the income distribution. In this model we can determine the management and education premia. We can also show that when our model is exposed to skill-upgrading it is capable of producing income dynamics similar to those observed in the Danish income distribution.

Keywords: income inequality, search model, skill-upgrading, organizational structure.

JEL codes: J3, J6, M5

We acknowledge financial support from the British Academy. We wish to thank Shaun Hargreaves-Heap, Sara Connolly, Michael Roos, Eric Smith, Christopher Pissarides, and participants at the PET 2010 Conference in Istanbul for useful comments. All remaining errors are ours.
\end{abstract}

*Department of Business Development and Technology, Aarhus University, CCP, ICOA and IZA. Address: Birk Center Park 15, DK 7400 Herning, Denmark. Email: afr@auhe.au.dk.

${ }^{\dagger}$ School of Economics, University of East Anglia. Norwich NR4 7TJ, United Kingdom. Email: o.poulsen@uea.ac.uk. 


\section{Introduction}

Over the last three decades, most developed countries have experienced increasing income inequality (OECD, 2007). A recent OECD report (OECD, 2011) pointed out that also traditionally low-inequality countries such as Denmark, Germany and Sweden experienced significant increases in income inequality during the 2000s. In Denmark the average annual percentage change in income was one percent over the period mid-1980s to late 2000s. But, income progression was very unequal across income deciles. While, the bottom decile experienced annual income growth of only 0.7 percent the top decile had earnings growth of 1.5 percent. Other sources also point towards increasing income inequality in Denmark. For example, Atkinson and Søgaard (2013) study income inequality in Denmark over the past century and find that income inequality at present is at a relatively low level - but that income inequality has been on the rise since the early 90 ies.

In this paper, we intend to shed light on the causes of the increasing income inequality observed in Denmark during the period 1992 to 2007. We do so using register-based employer-employee data. We find that income inequality has indeed increased in Denmark during this period. We also show that this increase occurred during a period where the inflow of highlyeducated workers into the labor market was substantial and management compensation grew steadily. To better understand this interplay between skill-upgrading, management compensation and income inequality, we propose an equilibrium search model where the firm has an explicit organizational structure. An important feature of this model is that the endogenously determined management and education premia (two important drivers for income inequality) can be established and studied. Furthermore, this model is capable of reproducing the dynamics in income inequality observed in Denmark over the sample period when it is subjected to skill-upgrading.

Our focus on skill-upgrading and management compensation as drivers for income inequality implies that our paper is in line with a large U.S. literature on income inequality (e.g., Katz and Murphy, 1992; Juhn, Murphy, and Pierce, 1993; Katz and Autor, 1999). ${ }^{1}$ This literature documents a substantial widening of U.S. income distribution during the 80s and establishes that the action in the income distribution is at the top income percentiles (where most managers are located). The literature also documents that the supply of highly-educated labor grew steadily in the U.S. during the 80s.

\footnotetext{
${ }^{1}$ Other seminal papers in the field (the list is by no means exhaustive) are Autor, Katz, and Kearney (2008), Bartel and Sicherman (1999), Bound and Johnson (1992), DiNardo, Fortin, and Lemieux (1996), Kopczuk, Saez, and Song (2010), Levy and Murnane (1992), Murphy and Welch (1992), and Piketty and Saez (2003).
} 
More recent papers by Autor, Katz, and Kearney (2008) and Autor, Levy, and Murnane (2003) have revisited the question of growing income inequality in the U.S. using data for the 90s. They find that the increase in income inequality has continued, however at a slower pace. On reason is that real wage growth was U-shaped in the U.S. in the 90 s. $^{2}$

Our analysis also complements the existing Danish literature on income inequality. A recent contribution by Neamtu and Westergård-Nielsen (2013) investigates changes in Danish income inequality with a focus on the effects of changing demographics, family formation and aging. Bjørnskov et. al. (2013) takes a related approach but include a discussion of social impacts and political economy. Finally, Atkinson and Søgaard (2013) take the longterm perspective and establish how income inequality has changed during the last 140 years. Our paper adds to this literature by investigating the interplay between skill-upgrading, management compensation and income inequality.

We start our analysis by investigating change in Danish income inequality using register-based employer-employee data for all private sector workers between 1992 and 2007. We establish three empirical results. First, in line with previous evidence, we document that Danish income inequality has been rising. Second, the employment share of highly educated individuals has increased substantially both in management and non-management. Third, all employee subgroups (defined by education level and organizational placement) have real income progression, but the growth rates are significantly higher for employees in managerial positions. Thus, the changes in Danish income inequality share many of the features found for the U.S., but it is also apparent that a pure skill story cannot fully account for the observed changes in income inequality, as there are significant differences in the ways management and non-management incomes evolve.

To better understand the dynamics in the income distribution, we build a theoretical model. The model is similar to existing hierarchical search models with on-the-job search; see Albrecht and Vroman (2002), Dolado et al. (2009), Gautier (2002), Gautier, Teulings, and van Vuuren (2006), Pissarides (1994), and Wong (2003). ${ }^{3}$ In these models, jobs are heterogeneous

\footnotetext{
${ }^{2}$ Autor, Levy, and Murnane (2003) argue that their findings follow from the fact that neither high-skill tasks nor low-skill tasks can be computerized (but average-skill tasks can). This implies a steady increase in the demand for workers with low and high education levels whereas the demand for individuals with medium-skills are in decline. These findings are not unique to the U.S. as extant work by Goos and Manning (2007) and by Goos, Manning, and Salomons (2009) show, that job polarization also occurs in most European countries (including Denmark) during this period.

${ }^{3}$ We stress that we use the terms 'hierachy' and 'hierachical' in a slightly different way
} 
and have skill requirements, and workers are heterogeneous in their education levels. These papers classify workers as either low- or highly-educated and jobs as either 'simple' or 'complex'. In this paper, we focus on explaining income inequality in a period of significant skill-upgrading and strong growth in management compensation. For that reason, we maintain the notion of highly- and less-educated workers. However, we explicitly distinguish between managerial and non-managerial jobs and refer to 'simple' jobs as 'non-management' jobs and 'complex' jobs as 'management' jobs.

On one important dimension, our model differs from previous work: we do not restrict the job search of less-educated employees. Existing models assume that management jobs ('complex' jobs) require a higher education. However, empirically, we see that a significant proportion of managers do not possess college or university degrees, and for that reason, we allow for the possibility that less-educated workers obtain management jobs. This changes the search behavior of less-educated workers and alters the model in interesting ways.

One implication of relaxing the job search assumption for less-educated workers is that we operate with four different education-job match types, whereas previous papers have only had three. To be more specific, denote a management and non-management job by $\mathrm{M}$ and NM, and low and high education as $\mathrm{L}$ and $\mathrm{H}$, respectively. Our model then allows for four match types: (H,NM), (L,NM), $(\mathrm{H}, \mathrm{M})$, and $(\mathrm{L}, \mathrm{M})$, whereas existing models exclude the latter. Furthermore, because the productivity of the worker depends on the worker's education level and job type, we impose the innocuous assumption that highly-educated workers are more productive than less-educated workers (conditional on job level), and we follow Lucas (1978) and Rosen (1982) and assume that workers in non-management have limited discretion over resources and hence are less productive than employees in management jobs (conditional on the worker's education level). Hence, the productivities of workers in each of these matches are ranked as follows: $(L, N M)<(H, N M)<(L, M)<(H, M)$.

These distinguishing features of our model generate two predictions about income inequality that match general empirical findings in the Danish register data and, more generally, in OECD countries. First, conditional on

than in the existing papers. In the latter, 'hierarchy' refers to a one-to-one mapping of workers to job types, where the highest worker type is assigned to the highest job type and vice versa (see Gautier, Teulings, and Vuuren (2006), p. 118). In this paper, 'hierarchy' refers to the internal structure of the firm. It is used to indicate that firms have a pyramidal structure, i.e. have more jobs in non-management than in management and that workers in management jobs are more productive than workers in non-management. For empirical evidence on this, see Lazear, Shaw, and Stanton (forthcoming). 
education levels, managers earn higher wages than non-managers. We refer to this as the 'management premium'. The management premium is endogenously derived in the model and follows from two sources: managers are more productive than non-managers and they do not search on the job. Hence, the firm rewards them for being more productive and for staying longer. This new feature of the model implies wage dispersion within education levels for both highly-educated and less-educated employees.

Second, contrary to other models with on-the-job-search, such as Gautier (2002) and Dolado et al. (2009), our model can generate an 'education premium' in both management and non-management, which implies that highly-educated workers earn more in both sectors. This result can only be obtained in models where less-educated workers can search for 'complex' jobs, which, in the context of our model, implies the presence of an internal labor market where both highly- and less-educated workers can obtain management jobs.

The equilibrium income distribution derived from our model is critically dependent on the productivity, the bargaining power, and the educational composition in the labor market. This implies that a shock to any of these parameters alters the income distribution by changing relative wages and employment shares. Prior research on income inequality has had a focus on the steady increase in the number of highly educated individuals who enter the labor market. We contribute to this research agenda by deriving the comparative statics for the steady state employment shares and wages, and find that the predicted effects of skill-upgrading are similar to the recently observed dynamics in the Danish income distribution. That is, skill-upgrading increases the employment shares of highly-educated employees, increases compensation for all employees, and leads to relatively higher income growth for workers with management jobs. Combined these effects increase income inequality.

The rest of the paper is organized as follows. In the next section, we describe the changes that have occurred in the Danish income distribution during recent years. In Section 3, we present the theoretical model, and the equilibrium is derived in Section 4. In Section 5, we present some comparative statics. Finally, Section 6 summarizes and concludes. Proofs are in the Appendix.

\section{The Danish Income Distribution}

In this section, we describe changes in Danish income distribution between 1992 and 2007. The main finding is that income inequality in the private sector in Denmark has been rising, caused by changes both in the employment 
composition and relative incomes of employees. Most pronounced is the increase in the employment share of highly-educated employees, but relative incomes have also been altered substantially, with income increasing more rapidly for managerial employees who are positioned at the upper income percentiles.

\subsection{The Data}

The empirical analysis is conducted using register-based employer-employee data from Denmark between 1992 and 2007. ${ }^{4}$ This database contains detailed information about all employers and employees. Of particular importance to the present analysis is the fact that employees and companies can be matched and that this information can be combined with further information on the employees' education levels, incomes, and job assignments. The database contains more than one million observations per year resulting in $18,406,618$ person-year observations in total.

We divided the sample into four employee groups: less-educated nonmanagers, highly-educated non-managers, less-educated managers, and highlyeducated managers. In order to be considered highly-educated, the employee must have at least a college degree (or in the Danish context, a Bachelor's degree). Managers are identified using the International Standard Classification of Occupations (ISCO) from the International Labor Organization (ILO). Defining a manager as an individual assigned to ISCO Major Group One, which comprises corporate managers and general managers, 4.4 percent of the sample are managers.

\subsection{The Income Distribution}

Table 1 contains descriptive statistics that characterize the income distribution. Less-educated employees in non-management jobs constitute the largest employee subgroup, representing almost 87 percent of the sample in 1992, but highly-educated non-managers also constitute a significant proportion of the employees (8 percent in 1992). The two management groups (highly and less-educated) are relatively small, with proportions between one and four percent.

\footnotetext{
${ }^{4}$ The resister data is known as the IDA-database (den Integrerede Database for Arbejdsmarkedsforskning) and is constructed by Statistics Denmark (www.dst.dk). The database contains detailed information on employers and employees from 1980 and onwards. The information on job assignment (ISCO codes from the International Labor Organization, www.ilo.org), that play a key role in our empirical analysis are only available from 1992, which is the reason we focus on the year 1992 to 2007.
} 


\section{[Table 1]}

Turning to income, it is clearly the case that income increases with education and job level. All income figures presented in the paper are annual gross real income in Euros, with 2000 as the base year. ${ }^{5}$ In 1992, the average income was 32,000 . In that year, less-educated employees in nonmanagement earned on average 30,000, whereas less-educated employees in management had incomes close to 47,000 on average. The highly-educated employees had substantially higher incomes. Highly-educated employees in non-management made on average 48,000 in 1992, and highly-educated workers in management had an average income of $74,000 .^{6}$

\subsection{Changes in the Income Distribution}

During the sample period, the income distribution was significantly altered, resulting in an increase in income inequality. To measure this increase we use income inequality statistics similar to Katz and Autor (1999) and Autor, Katz and Kearny (2008). We find that the standard deviation of log income increases from 0.65 in 1992 to 0.80 in 2007, and that the Gini coefficient increases from 0.42 in 1992 to 0.57 in 2007 (see Table 2). Alternative measures of income inequality are the differences in log percentiles. For example, the 90-10 difference was 1.42 in 1992 but in 2007 it had increased to 1.88 . Hence, all of these measures of income inequality unambiguously point in the direction of increasing inequality. ${ }^{7}$

[Table 2]

\footnotetext{
${ }^{5}$ This measure of pay contains both fixed and variable pay components.

${ }^{6}$ While the compensation packages in Denmark for managers resemble those in other parts of Europe, they differ greatly from those used in the US (see Eriksson and Lausten, 2000). Eriksson and Lausten stress that a relatively small proportion of Danish firms have bonus and/or commission systems for their managers, and they show that only 2025 percent of all managers and a third of the CEOs are paid bonuses or commissions. Furthermore, their share of total compensation varies between 10 and 12 percent. They also refer to studies based on US and UK data that document that base pay in those countries only account for about 50-60 percent of total compensation.

${ }^{7}$ Note that our study focuses on gross incomes for employees working in the private sector. Other studies such as Neamtu and Westergaard-Nielsen (2013) and Bjørnskov et. al., 2012) focus on household incomes in Denmark. In such studies, the rise in income inequality is more modest. An interesting aspect of the report by Bjørnskov et. al. is that they in addition to addressing changes in gross income inequality also consider changes in income inequality when taxes and transfers are taken into account. Atkinson and Søborg (2013) also dive into a discussion of the impacts of the tax system on Danish income inequality.
} 
Taking a closer look at the changes in income we find that, overall, real income has increased by 14.29 percent or close to one percent per year. However, as depicted in Figure 1, the growth in income was unequal and increased in the income percentile. That is, income growth increases steadily from the lowest to the highest percentiles, but at the 90th percentile the increase becomes particularly steep. At the highest percentiles income growth over the period 1992 to 2007 exceeds median income in the economy.

[Figure 1]

One explanation for the high growth in income at top percentiles is that managerial compensation has increased significantly duing the sample period (see Table 1). While income progression in non-management jobs has been relatively modest ( 2 percent for highly-educated and 10 percent for less-educated), management compensation has increased substantially (27 percent for highly-educated and 31 percent for less-educated). It is also clear from Figure 1 that most managers (as expected) are located at the top income percentiles where income progression is highest. Hence, the higher management compensation is causing income at top percentiles to grow relatively fast and thus pushes the upper tail of the income distribution even further to the right, leading to an increase in income inequality.

The employment composition has also been altered during the sample period. In particular, the increase in the share of highly-educated employees in the workforce is noticeable (see Table 1 ). In the early 90 s, 9 percent of the workforce were highly-educated, but by 2007, this proportion had increased to 18 percent. The composition of the managerial workforce changed in a similar way: in 1992, less-educated employees clearly represented the larger share of the management workforce, but by the late 2000s, the gap between less-educated and highly-educated managers was reduced significantly. Among non-management workers, the share of highly-educated workers rose from 8 percent to 17 percent - an increase of more than 100 percent. In contrast, the employment share of less-educated workers in non-management jobs has been declining steadily, from a level of 87 percent in 1992 to less than 80 percent in 2007.

To better understand the nature of the skill-upgrading we present the year-by-year worker mobility transition matrix in Table 3 . The non-management states are highly stable. More than 95 percent of both less- and highlyeducated employees working in non-management are working at the same job level with the same education level in the following year. For management employees, the numbers are 67 percent for the less-educated and 73 percent for the highly-educated. The transition probabilities show very lit- 
tle formal skill-upgrading on-the-job. Less-educated managers have a 0.13 percent probability of transiting to the highly-educated management group in a given year. The probability of moving to the highly-educated nonmanagement group is even lower. Less-educated non-managers are not moving to the highly-educated manager category, and only 0.22 percent move to the highly-educated non-manager category. If we instead look at the flows into and out of the firm, we can establish that, across the years, 23.27 percent of those hired into management are highly-educated, whereas only 21.52 percent of those leaving management are highly-educated. For the non-management group, 10.89 percent of those hired are highly-educated and only 8.85 percent of those leaving have a higher education. Hence, these findings clearly show that there is very little on-the-job skill-upgrading and that the significant skill-upgrading observed in the data is due to the hiring of new personnel with higher levels of education.

[Table 3]

\subsubsection{A simulation}

Another way to illustrate the link between skill-upgrading, management compensation and income inequality is through simulation, see Table 4. Using data from 1992 and 2007, we first estimate the following log-wage regression:

$$
\ln W=\alpha+\gamma \text { Man }+\eta H i g h+X^{\prime} \beta+\epsilon,
$$

where $\ln W$ is log-income, Man is a dummy for working in management, High is a dummy for being highly-educated and $X$ is a matrix of controls that contains quadratics in age and experience and a dummy for gender. The model's parameters are: $\alpha, \gamma, \eta$ and $\beta$, where we denote $\gamma$ the management premium and $\eta$ the education premium. $\epsilon$ is an error term.

Based on separate regressions for each year, we predict wages $(\widehat{\ln W})$ and calculate the Gini coefficients. The predicted Gini coefficient for 1992 is 0.225 and for 2007 it is 0.295 . Hence, the predicted Ginis are somewhat lower than those based on actual data (as the regression is leaving the unobserved heterogeneity in the error term), but the result that income inequality has increased is maintained in the predicted Gini coefficients.

[Table 4]

In the first simulation, we investigate the effects of skill-upgrading on income inequality. The proportion of highly-educated workers in 1992 is 9.3 
percent and in 2007 it is 17.9 percent. So, to simulate the effect of skillupgrading, we use the data and the estimated coefficient from 1992, but we then randomly 'upgrade' the education level for 8.6 percent of less-educated non-managers such that the proportion of highly-educated employees mirrors that for 2007. The predicted Gini coefficient we obtain is 0.201 . This Gini is somewhat lower than the one observed in both 1992 and 2007. The reason is that the upgrade of the education level has 'moved' a significant proportion of the low income earners into the middle of the income distribution. Hence, skill-upgrading has a tendency to reduce income inequality. In the second simulation, we focus on the consequences of the rising management premium on income inequality. We evaluate the effect using the data and estimated coefficients from 1992, and then we change the management premium to its 2007 level. This exercise produces a predicted Gini coefficient of 0.297, which is similar to the predicted Gini from 2007. In a final simulation, we evaluate the joint effects of skill-upgrading and the rising management premium and obtain a predicted Gini coefficient of $0.272 .{ }^{8}$ These results show that the combination of skill-upgrading and the rising management premium can explain a significant proportion of the observed increase in income inequality.

\section{The Model}

Time is assumed to be continuous. Consider a firm with management (M) and non-management $(\mathrm{N})$ sectors that face a labor force of $\Omega$ workers. The workers employed by the firm are members of the internal labor market, denoted by $I$; the remaining individuals constitute the external labor force, $E$. The size of the total labor force is normalized to unity, i.e., $\Omega=I+E=1$. All workers are distinguished by an observable level of education, where the proportion $\pi$ of the workers is less-educated and the remaining $1-\pi$ is highlyeducated. Highly-educated workers will be referred to as $\mathrm{H}$ workers, while less-educated workers will be referred to as $\mathrm{L}$ workers. We use the notation $k=L, H$ to denote a worker's education level and $\tau=N, M$ to denote a sector.

\footnotetext{
${ }^{8}$ Note that the predicted Gini coefficient for the simulation where we investigate the joint effects of skill-upgrading and the rising management premium is 0.272 , whereas the predicted Gini coefficient based on the 2007 data is 0.295 . The difference between these two numbers can be contributed to other changes in workforce composition or 'prices' between 1992 and 2007. Descriptive statistics for the two years show that more women have joined the workforce and that the workforce has become slightly older and more experienced over time. For a discussion of these complementary drivers for income inequality, see for instance Neamtu and Westergaard-Nielsen (2013).
} 
When the firm opens up a vacancy, its type is determined ex-ante. The firm can open up vacancies in management and non-management. We denote vacancies in non-management $v_{N} \cdot{ }^{9}$ Vacancies in management are denoted $v_{k M}$ and have skill requirements, i.e., they can only be filled by individuals who have the required education level $k=L, H$. For reasons explained below, individuals in management jobs have the highest productivity. This implies that employees with the required level of education from both the non-management sector of the internal labor market $i_{k N}$ and the external labor market $e_{k}$ apply for management vacancies $v_{k M} \cdot{ }^{10}$ It also implies that because managers $i_{k M}$ have no incentives to search for a new job, only external candidates apply for non-management jobs.

Workers and vacancies meet each other randomly according to the CobbDouglas matching function. This means that the matching of a job in the non-management sector and a worker of any skill level from outside the firm is given by

$$
x_{N}=x_{N}\left(v_{N}, e_{L}+e_{H}\right)=\left(v_{N}\right)^{\alpha}\left(e_{L}+e_{H}\right)^{1-\alpha} .
$$

In the management sector, workers of skill level $k$ are matched with vacancies

\footnotetext{
${ }^{9}$ Note that we denote a vacancy in the non-management sector simply as $v_{N}$ where $v_{L N}=v_{H N}=v_{N}$, since both highly-educated and less-educated workers can apply for a job in the non-management sector.

${ }^{10}$ Note that this setup mirrors the one found in, for example, tournament theory (Lazear and Rosen, 1981), which is an alternative (partial equilibrium) setup that can be used to model internal promotions and external recruitment. Tournament theory provides an intuitive framework for modeling promotions in firms, and it is interesting to note that promotions in tournament games and promotions (workers matched to management jobs) through a matching function are qualitatively indistinguishable. The reason is that promotions from the contestant pool in a tournament game appear random ex post. That is, in tournament theory, individuals are competing for a fixed number of prizes (promotions). The prizes (pay gaps between management and non-management jobs that are set ex ante by the firm) motivate employees to exert effort, and because employees are identical in terms of ability, they are all motivated to exert the same level of effort. Hence, because productivity is a function of ability, effort, and luck, the luck component determines who is promoted. When this framework is extended to situations with heterogeneous individuals (such as settings where individuals have different levels of ability or education), competition is no longer "fair," and to mitigate this issue, firms should set up multiple tournaments such that each tournament only involves similar individuals (McLaughlin, 1988). Furthermore, firms should make use of both internal promotions and external recruitment when filling management positions to discourage workers from colluding (Chan, 1996). Hence, while our model abstracts from the underlying motivational story, its structure mirrors that of tournament theory. That is, management jobs are filled with both internal and external candidates who have the appropriate education level.
} 
requiring skill $k$, where $k=L, M$, as follows:

$$
x_{k M}=x_{k M}\left(v_{k M}, e_{L}+i_{k N}\right)=\left(v_{k M}\right)^{\alpha}\left(e_{L}+i_{k N}\right)^{1-\alpha} .
$$

The labor market flows are illustrated in Figure 2. Individuals in the external labor market may get jobs in both non-management and management. When an individual obtains employment in the non-management sector of a firm, they have an option to be promoted. Since jobs in management have educational requirements, both less- and highly-educated employees from the non-management sector can be promoted. All employees have an exogenous separation risk; hence, there are flows from both the management and nonmanagement sectors back into the external labor market.

[Figure 2]

A worker's output is denoted by $y_{k \tau}$, where $y_{k \tau}=\mu_{k \tau} y$; $y$ is the level of output produced by less-educated workers in non-management jobs and $k=L, H, \tau=N, M$. We make three assumptions about workers' productivity. First, highly-educated workers in any given job are always more productive than less-educated workers in the same job type, i.e., $\mu_{H \tau}>\mu_{L \tau}$. Second, we follow Lucas (1978) and Rosen (1982) in assuming that workers in nonmanagement jobs have limited discretion over resources and hence are less productive than employees in management jobs, who control resources, i.e., $\mu_{k M}>\mu_{k N}$. And finally, we assume that less-educated workers in management are more productive than highly-educated workers in non-management jobs. These three assumptions ensure that $1=\mu_{L N}<\mu_{H N}<\mu_{L M}<\mu_{H M}$.

Labor market tightness in the market for non-management jobs is defined as

$$
\theta_{N}=\frac{v_{N}}{\left(e_{L}+e_{H}\right)}
$$

Similarly, the labor market tightness variables in the market for management jobs of skill $k, k=L, M$ are defined as

$$
\theta_{k M}=\frac{v_{k M}}{\left(e_{k}+i_{k N}\right)} .
$$

This allows us to define the rates at which a $k$-type job in the non-management sector meets a worker of type $k$ as

$$
q_{N}\left(\theta_{N}\right)=\frac{x_{N}}{v_{N}},
$$


where $k=L, H$ and $q_{k N}=q_{N}$. Similarly, a $k$-type job in the management sector meets a worker of skill level $k, k=L, M$, as follows:

$$
q_{k M}\left(\theta_{k M}\right)=\frac{x_{k M}}{v_{k M}} .
$$

We also define the rates at which a worker of type $k$ encounters a vacancy in the non-management sector and the management sector as

$$
\begin{gathered}
p_{N}\left(\theta_{N}\right)=\frac{x_{N}}{\left(e_{L}+e_{H}\right)}, \\
p_{k M}\left(\theta_{k M}\right)=\frac{x_{k M}}{\left(e_{k}+i_{k M}\right)},
\end{gathered}
$$

where $k=L, H$.

\section{Payoff Functions and Wage Determination}

The firm maximizes the present discounted value (PDV) of expected profits, and the individual maximizes the PDV of the expected income stream. The firm decides if a particular vacancy should be opened or not. The individual assesses if the job offer received is sufficiently attractive, taking into account alternatives such as other job opportunities or continued job search. When the worker and the firm meet, they bargain over the wage. In the following sections, we describe these processes.

\subsection{The Firm}

The firm advertises three different types of jobs: a vacancy in non-management and two vacancies in management. The management jobs require different levels of education, but the non-management vacancy can be filled with a worker of any educational level. Hence, in practice, the firm employs up to four different employee types: less-educated in non-management jobs, highlyeducated in non-management jobs, less-educated in management jobs, and highly-educated in management jobs. These types generate different levels of profits, since they differ in their productivities and, as will be shown below, have different costs.

We denote the expected PDV of having a vacant non-management job by $V_{k N}$, where $V_{L N}=V_{H N}$. The expected PDV of the vacancy depends on the potential worker's productivity. For this reason, we denote the PDV of a vacancy filled with an employee of type $k$ by $J_{k N}$. Furthermore, under perfect competition, the PDV of expected profit from a vacant non-management job, 
$V_{k N}$, equals the rate of return. Recalling that the job is filled by a highlyeducated or a less-educated worker with probability $q_{N}$, the rate of return can be written as the difference between the vacancy cost of a non-management job, $c_{N}$, and the expected return from having the job filled. The expected return from having the position occupied is equal to the sum of the returns generated by less-educated employees and the returns generated by highlyeducated employees weighted by the relative population size. This implies that the following equation will be satisfied in equilibrium ${ }^{11}$ :

$$
r V_{k N}=\frac{x_{N}}{v_{N}}\left[\frac{e_{L} J_{L N}+e_{H} J_{H N}}{e_{L}+e_{H}}-V_{k N}\right]-c_{N},
$$

where $r$ is the rate of return and $V_{L N}=V_{H N}$. This equation says that the expected income stream for a vacancy in the non-management sector is equal to the probability $\left(\frac{x_{N}}{v_{N}}\right)$ that the vacancy meets either a highly or lesseducated worker times the expected rents of a match with this worker, which depends on the stock of less- and highly-educated workers in the external labor market and on the composition of the workforce.

Using the same reasoning, the PDV of expected profit for a non-management job filled by a worker of type $k, J_{k N}$, equals its return. In this case, the return is the output produced by the worker, $y_{k N}$, minus $w_{k N}$, the wage paid to the worker. In addition to this, the eventual loss of revenue that occurs if the worker and the firm separate, which happens with probability $s$, and the potential loss if the worker finds a job in the management sector must be added. Thus,

$$
r J_{k N}=y_{k N}-w_{k N}+s\left(V_{k N}-J_{k N}\right)+p_{k M}\left(V_{k N}-J_{k N}\right) .
$$

Similar expressions can be derived for management. When the PDV of expected profit for a vacant management job, $V_{k M}$, equals its rate of return, we obtain:

$$
r V_{k M}=q_{k M}\left(J_{k M}-V_{k M}\right)-c_{k M},
$$

where $c_{k M}$ are the vacancy costs.

Finally, recalling that management employees do not search for other employment, it follows that when equating the PDV of expected profit from a filled management job, $J_{k M}$, to the return, we get

$$
r J_{k M}=y_{k M}-w_{k M}+s\left(V_{k M}-J_{k M}\right),
$$

\footnotetext{
${ }^{11}$ This equation is similar to equation (16) in Gautier (2002).
} 
where $w_{k M}$ are the wages paid to an employee of type $k$ working in management.

\subsection{The Workers}

A worker of type $k$ earns $w_{k N}$ when employed in a non-management job and $w_{k M}$ when working in a management job. For simplicity, we normalize an employee's income in the external labor market to zero.

Let $E_{k}$ be the PDV of income for a type $k$ worker in the external labor market. The individual may move to a job in either non-management or management. The first event occurs with probability $p_{N}$. The worker would then earn the PDV of the expected income stream $W_{k N}$ until a job in management arrives or a separation from the firm occurs. If the individual instead gets a job in management (which occurs at rate $p_{k M}$ ), the PDV of the expected income stream is $W_{k M}$ until separation. Hence, $E_{k}$ is equal to the expected gain when obtaining a job:

$$
r E_{k}=p_{N}\left(W_{k N}-E_{k}\right)+p_{k M}\left(W_{k M}-E_{k}\right) .
$$

The payoff to a worker in a non-management job is given by the wage $w_{k N}$, the risk premium against separation, and the option value of being promoted. It follows that:

$$
r W_{k N}=w_{k N}+s\left(E_{k}-W_{k N}\right)+p_{k M}\left(W_{k M}-W_{k N}\right) .
$$

Finally, employees already working in management do not search for a new job, but they face an exogenous separation rate, $s$. Thus,

$$
r W_{k M}=w_{k M}+s\left(E_{k}-W_{k M}\right) .
$$

\subsubsection{Wage Determination}

Wage determination in this model is similar to that of Pissarides (1994, 2000). In equilibrium, occupied jobs in management and non-management generate pure economic rent, and the wages paid by the firm to its employees pass along some of the rent. In the Pissarides model, workers perform onthe-job searches. As pointed out by Shimer (2006), this implies that the set of feasible payoffs over which wages are bargained is not convex and that a unique solution to the Nash bargaining rule used by Pissarides (1994, 2000) may no longer exist. We overcome this problem by using the solution proposed in Dolado et al. (2009), that assumes that wages are determined 
by a surplus splitting rule after the job is accepted, with unemployment as a threat point. This surplus sharing rule is

$$
\left(1-\beta_{k \tau}\right)\left[W_{k \tau}-E_{k}\right]=\beta_{k \tau}\left[J_{k \tau}-V_{k \tau}\right],
$$

where $k=L, H, \tau=N, M, V_{k, N}=V_{N}$, and $0<\beta_{k \tau}<1$ represents an employee's bargaining power.

\subsection{Steady State}

For $k=L, H$ and $\tau=N, M$, a steady state is a set of value functions for $W_{k \tau}, J_{k \tau}, V_{k M}, V_{N}, E_{k}$ that satisfy (10) to (17), and a vector $\left(e_{k}, \theta_{N}, \theta_{k M}\right.$, $\left.i_{k \tau}, v_{N}, v_{k M}\right)$. We derive the steady state by imposing two assumptions: first, the labor market flows are stable and, second, all profit opportunities in the market are exhausted such that $V_{k N}=0$ and $V_{k M}=0$.

We demonstrate the existence of a steady state by imposing a number of sufficient conditions (see details in the Appendix). Our existence proof is for the case where all workers have the same bargaining power. ${ }^{12}$

There are five sufficient conditions. One condition is $\pi>1 / 2$. Recall that $\pi$ is the proportion of less-educated workers in the workforce and for Denmark this proportion is 0.82 in 2007 according to Table 1.

The second condition imposes an upper limit on the productivity of highly-educated non-managers. A numerical evaluation of the condition (using the data from Table 1) implies that the productivity of highly educated non-managers cannot be six times higher than the productivity of less-educated non-managers; something which will be trivially satisfied in Denmark and in other countries.

The remaining three conditions are somewhat harder to interpret and we refer the reader to the Appendix for details.

Proposition 1. There exists a steady state under the conditions (28)(32), stated in the Appendix. ${ }^{13}$ The steady state values are:

\footnotetext{
${ }^{12}$ This assumption reflects the principle of insufficient reason: we have researched the literature and have not been able to find any empirical studies that estimate the bargaining powers for Denmark or any other country. In fact, it seems very difficult if not impossible to estimate the bargaining powers in the Nash bargaining solution. In the absence of any information about the bargaining powers, we have therefore assumed that they are the same. Indeed, most studies, in the absence of data, simply assume that all bargaining powers are equal to one-half. Our assumption, that the bargaining powers are the same (but that they do not necessarily equal one-half) is thus slightly more general than the typical specification. We also studied a more general model, where bargaining powers could differ; in this setup there exists a steady state with the same wage ranking as in the model with identical bargaining powers.

${ }^{13}$ We should note that the sufficient conditions for existence do not imply uniqueness.
} 


\section{Wages:}

- Wages in non-management are:

$$
w_{k N}=\frac{\beta_{k N}\left(r+s+p_{k M}+p_{N}\right) \mu_{k N} y}{r+s+p_{k M}+\beta_{k N} p_{N}} .
$$

- Wages in management are:

$$
w_{k M}=\frac{\beta_{k N} p_{N}\left(1-\beta_{k M}\right) \mu_{k N} y}{r+s+p_{k M}+\beta_{k N} p_{N}}+\beta_{k M} c_{k M} \theta_{k M}+\beta_{k M} \mu_{k M} y
$$

where $\mu_{H M}>\mu_{L M}>\mu_{H N}>\mu_{L N}=1$.

\section{Employment shares:}

- The shares of type $k$ workers not employed in the firm are:

$$
e_{k}=\frac{s \pi_{k}}{\left(s+p_{k M}+p_{N}\right)} .
$$

- The employment shares of non-management employees are:

$$
i_{k N}=\frac{s p_{N} \pi_{k}}{\left(s+p_{k M}+p_{N}\right)\left(s+p_{k M}\right)} .
$$

- The employment shares of management employees are:

$$
i_{k M}=\frac{p_{k M} \pi_{k}}{s+p_{k M}},
$$

where $\pi_{L}=\pi$ and $\pi_{H}=1-\pi$.

Thus the income distribution is: $w=w_{k \tau}$ with probability $i_{k \tau}$. Proof. See the Appendix. 


\subsection{The Management and Education Premia}

Important new features in our model are the management and education premia and for this reason they will be studied in more detail in this section.

First, the management premium for a type $k$ worker, $k=L, H$, is defined as the wage difference $w_{k M}-w_{k N}$. A sufficient condition for the management premium to be non-negative is

$$
\beta_{k M} \mu_{k M} \geq \beta_{k N} \mu_{k N}
$$

By assumption $\mu_{k M}>\mu_{k N}$. Hence, there is a positive management premium whenever $\beta_{k M} \geq \beta_{k N}$. Thus there exists a positive management premium when bargaining powers are equal. In fact, the premium exists under weaker conditions. In the Appendix we prove the following: for each fixed $\beta_{k N}$ there is a unique critical value of $\beta_{k M}$, denoted $\beta_{k M}^{*}$, where $0<\beta_{k M}^{*}<\beta_{k N}<1$, such that the management premium is strictly negative for all $\beta_{k M}$ satisfying $0 \leq \beta_{k M}<\beta_{k M}^{*}$ and strictly positive for all $\beta_{k M}>\beta_{k M}^{*}$. In other words, the management premium for each type is strictly positive whenever the type has more bargaining power in the management than in the non-management sector, but the premium is strictly positive even when this condition fails, as long as bargaining power in the management sector is sufficiently high.

This result can be explained intuitively as follows. Managers are more productive than non-managers and they stay longer on the job as they do not perform on-the-job searches. In pay setting firms will exploit that managers do not search on-the-job and when the bargaining power of managers is relatively low, non-managers' wages may exceed managers' wages. However, the management premium is strictly positive for higher values of the managers' bargaining power, because the firm rewards managers proportionally more for staying longer in a job and for being more productive than non-management workers.

Second, a positive education premium follows from the ranking of wages. This is an important result because of its empirical backing. It is also an important result because earlier models (such as Gautier, 2002 and Dolado et al., 2009) produced the somewhat counter-intuitive result that less-educated workers in 'simple'/non-managerial jobs earned more than their highly-educated coworkers working similar jobs. These models were also unable to establish an education premium in the management sector; as they would have been unable to produce a management premium for less-educated workers. 


\section{Comparative Statics: Responses to Skill- Upgrading}

In this section we investigate how skill-upgrading affects the dynamics of the income distribution. The main results from our comparative statics analysis are summarized in Proposition 2.

Proposition 2. An increase in $1-\pi$ (skill-upgrading) results in:

- An increase in $\theta_{N}, \theta_{L M}$, and $\theta_{H M}$

- A decrease in the employment share of less-educated employees in both management and non-management jobs

- An increase in the employment share of highly-educated employees in both management and non-management jobs

- An increase in $1-\pi$ also increases the wages of all employees. Furthermore, wages of management workers increase more than wages of non-management workers

Proof. See the Appendix.

The effect of skill-upgrading on wages and employment shares can be explained as follows. Skill-upgrading, i.e., a fall in $\pi$, means that the proportion of less-educated workers in the total workforce declines. There are now fewer less-educated workers competing for the existing vacancies in nonmanagement and management, implying that more highly-educated workers will be employed in non-management jobs. At the same time, it will allow less-educated workers to be promoted faster to low-skill jobs in management. Hence, in order to attract and retain workers in the non-management sector, the firm has to increase wages in this sector. This benefits all workers employed in the non-management sector. In the management sector, low-skill vacancies are now harder to fill (due to the fall in the number of applicants), and as a result, wages for less-educated employees in management will increase. For highly-educated workers, skill-upgrading means that there is less competition from less-educated for non-management jobs, but more competition from other highly-educated workers for any type of job. For a given number of vacancies, this means that labor market tightness for highlyeducated management jobs will initially fall.

However, skill-upgrading induces firms to open more vacancies for the highly-educated and fewer vacancies for the less-educated in the managerial 
sector. Skill-upgrading also means that the average worker that the firm meets will be more educated and thus more productive, generating a higher match value for the firm than previously. If the number of vacant jobs for the highly-educated workers increases in the management sector, then labor market tightness for highly-educated management jobs $\left(\theta_{H M}\right)$ increases. This means that the job finding rate for managerial skilled jobs increases, implying that wages in the non-managerial jobs have to rise further, and so on and so forth... The result is that wages in all jobs rise. The fact that the wages of managers (both less- and highly-educated) rise faster than the wages of non-managers is evident from the wage expressions derived in Proposition 1: as both labor market tightness parameters in the management sector increase, part of the "reward" received by managers (the term $\beta_{k M} c_{k M} \theta_{k M}$ ) also increases.

In conclusion, we see that skill-upgrading increases the employment share of highly-educated employees and drives up wages for all employees. Furthermore, the wages of managers increase more than the wages of non-managers. Thus, when our model is exposed to skill-upgrading it is capable of replicating the observed changes in the Danish income distribution between 1992 and 2007.

\section{Conclusion}

Income inequality has risen in most developed countries during recent decades. In this paper, we present an equilibrium search model that makes it possible to study the mechanisms leading to this change in income distribution. In particular, the effects resulting from skill-upgrading can be analyzed and explained. A detailed analysis shows that when our model is exposed to skill-upgrading it is capable of replicating the recent dynamics in the Danish income distribution. That is, it produces an increase in the employment share of highly-educated employees and drives up compensation for all employees, particularly for those working in management. This in turn leads to increasing income inequality.

An innovation of our model is that we explicitly model the structure of the firm (i.e., we allow for a non-management sector and a management sector). This allows us to endogenously establish a management premium and thus provide an explanation for why observationally identical employees (in terms of education) are paid different wages; an issue that has been discussed extensively in the literature (see Mortensen, 2003). Furthermore, modeling of the firm's structure also turns out to be essential for understanding the observed increase in income inequality, as a significant contributor to the 
widening of the income distribution is the relatively high income growth of managers. The present paper attempts to model and understand the interplay between skill-upgrading, management compensation and income inequality.

\section{References}

Albrecht, J., and S. Vroman. 2002. A matching model with endogenous skill requirements. International Economic Review, 43: 283-305.

Atkinson, A. B., and J. E. Søgaard. 2013. The long-run history of income inequality in Denmark: Top incomes from 1870 to 2010. EPRU working paper series 2013-01, Copenhagen University, Denmark.

Autor, D., L. Katz, and M. Kearney. 2008. Trends in U.S. wage inequality: Revising the revisionists. The Review of Economics and Statistics, 90: 300-323.

Autor, D., F. Levy, and R. Murnane. 2003. The skill content of recent technological change: an empirical exploration. Quarterly Journal of Economics, 118: 7-72.

Bartel, A., and N. Sicherman. 1999. Technological change and wages: an interindustry analysis. The Journal of Political Economy, 107: 285-325.

Bjørnskov, C., I. Neamtu, and N. Westergård-Nielsen. 2012. Growing inequality and its impacts in Denmark. The GINI Project: Country Report for Denmark.

Bound, J., and G. Johnson. 1992. Changes in the structure of wages in the 1980s: an evaluation of alternative explanations. American Economic Review, 82: 371-392.

Chan, W. 1996. External recruitment versus internal promotion. Journal of Labor Economics, 14: 555-570.

Dolado, J. J., M. Jansen, and J. F. Jimeno. 2009. On-the-job search in a matching model with heterogeneous jobs and workers. The Economic Journal, 119: 200-228.

DiNardo, J., N. Fortin, and T. Lemieux. 1996. Labor market institutions and the distribution of wages, 1973-1992: a semiparametric approach. Econometrica, LXIV, 1001-1044.

Eriksson, T. and M. Lausten. 2000. Managerial pay and firm performance - Danish evidence. Scandinavian Journal of Management, 16: 269286.

Gautier, P. 2002. Unemployment and search externalities in a model with heterogeneous jobs and workers. Economica, 69: 21-40. 
Gautier, P., C. N. Teulings, and A. van Vuuren 2006. Labor Market Search with Two-Sided Heterogeneity: Hierarchical versus Circular Models. Contributions to Economic Analysis, 275: 117-132.

Goos, M., and A. Manning. 2007. Lousy and lovely jobs: The rising polarization of work in Britain. Review of Economics and Statistics, 89: 118-33.

Goos, M., A. Manning, and A. Salomons. 2009. Job polarization in Europe. American Economic Review: Papers 63 Proceedings, 99: 58-63.

Juhn, C., K. M. Murphy, and B. Pierce. 1993. Wage inequality and the rise in returns to skill. The Journal of Political Economy, 101: 410-442. Katz, L. F., and D. H. Autor. 1999. Changes in the wage structure and earnings inequality. In O. Ashenfelter and D. Card, Handbook of Labor Economics, 3A, Ch. 26, Elsevier.

Katz, L. F., and K. M. Murphy. 1992. Changes in relative wages, 19631987: supply and demand factors. The Quarterly Journal of Economics, 107: $35-78$.

Kopczuk, W., E. Saez, and J. Song. 2010. Earnings inequality and mobility in the United States: evidence from Social Security data since 1937. Quarterly Journal of Economics, 125: 91-128.

Lazear, E. P., and S. Rosen. 1981. Rank-order tournaments as optimum labor contracts. The Journal of Political Economy, 89: 841-864.

Lazear, E. P., K. Shaw and C. Stanton. forthcoming. The value of bosses. Journal of Labor Economics.

Levy, F., and R. J. Murnane. 1992. U.S. earnings levels and earnings inequality: a review of recent trends and proposed explanations. Journal of Economic Literature, 30: 1333-1381.

Lucas, R. E. 1978. On the size distribution of business firms. The Bell Journal of Economics, 9: 508-523.

McLaughlin, K. J. 1988. Aspects of tournament models: a survey. In R. Ehrenberg, Research in Labor Economics, Vol 9: 225-256, Greenwich, CT: JAI.

Mortensen, D. 2003. Wage dispersion: why are similar people paid differently? Cambridge: MIT Press.

Murphy, K. M., and F. Welch. 1992. The structure of wages. The Quarterly Journal of Economics, 107: 285-326.

Neamtu, I., and N. Westergaard-Nielsen. 2013. Sources and impact of rising inequality in Denmark, mimeo, Copenhagen Business School.

OECD. 2007. Employment Outlook.

OECD. 2011. Divided we stand: Why inequality keeps rising.

Pikkety, T., and E. Saez. 2003. Income inequality in the United States 1913-1998. The Quarterly Journal of Economics, 118: 1-38. 
Pissarides, C. A. 1994. Search unemployment with on-the-job search. The Review of Economic Studies, 61: 457-475.

Pissarides, C. A. 2000. Equilibrium unemployment theory, second edition. Cambridge, MA: MIT Press.

Rosen, S. 1982. Authority, control and the distribution of earnings. The Bell Journal of Economics, 11: 311-323.

Shimer, R. 2006. On-the-job search and strategic bargaining. European Economic Review, 50: 811-830.

Wong, L. 2003. Can the Mortensen-Pissarides Model with Productivity Changes Explain U.S. Wage Inequality? Journal of Labor Economics, 21: 70-105. 


\section{Appendix}

\subsection{Deriving the Wages of non-management and Man- agement Employees}

We assume $\mu_{L N}=1$ and that $y_{k \tau}=\mu_{k \tau} y$. The wages of each type of employee in different jobs follow from the sharing rule (17) and equations (12), (14), and (16). First,

$$
r E_{k}=p_{N} \frac{\beta_{k N}\left(\mu_{k N} y-w_{k N}\right)}{\left(1-\beta_{k N}\right)\left(r+s+p_{k M}\right)}+p_{k M} \frac{\beta_{k M} c_{k M}}{\left(1-\beta_{k M}\right) q_{k M}} .
$$

Using (24) to substitute for $E_{k}$ in equations (12) and (13), we get

$$
\begin{gathered}
w_{k N}=\frac{\beta_{k N}\left(r+s+p_{k M}+p_{N}\right) y}{r+s+p_{k M}+\beta_{k N} p_{N}} \\
w_{k M}=\frac{\beta_{k N}\left(1-\beta_{k M}\right) \mu_{H N} y p_{N}}{r+s+p_{H M}+\beta k N p_{N}}+\beta_{k M} c_{k M} \theta_{k M}+\beta_{k M} \mu_{k M} y .
\end{gathered}
$$

\subsection{Deriving the Steady State Employment Shares}

The steady state condition equates the flow of workers into a given job to the flow of workers out of that job. The flows in and out of non-management jobs can be expressed as

$$
p_{N} e_{k}=\left(s+p_{k M}\right) i_{k N}
$$

and in management, we have

$$
p_{k M}\left(e_{k}+i_{k N}\right)=s i_{k N}
$$

since

$$
i_{k N}+i_{k M}+e_{k}=\pi_{k}
$$

where $\pi_{k}=\pi$ if $k=L$, and $\pi_{k}=1-\pi$ if $k=H$. It follows that

$$
\begin{gathered}
e_{k}=\frac{s \pi_{k}}{\left(s+p_{k M}+p_{N}\right)} \\
i_{k M}=\frac{p_{k M} \pi_{k}}{\left(s+p_{k M}\right)}
\end{gathered}
$$

and 


$$
i_{k N}=\frac{s p_{N} \pi_{k}}{\left(s+p_{k M}+p_{N}\right)\left(s+p_{k M}\right)}
$$

\subsection{Existence of Equilibrium}

The existence proof is standard: we need to show that the determinant of the Jacobian matrix associated with the following equations (25) and (26) is non-zero in the steady state:

$$
\begin{gathered}
F_{1}=c_{N} \theta_{N}^{1-\alpha}=\frac{(1-\pi)\left(1-\beta_{L N}\right) \lambda_{L+1} \mu_{H N} y}{\left(\pi \theta_{H M}^{\alpha}-\pi \theta_{L M}^{\alpha}+\lambda_{L+1}\right)\left(\lambda_{H}+\beta_{H N} \theta_{N}^{\alpha}\right)} \\
+\frac{\pi \lambda_{H+1}\left(1-\beta_{L N}\right) y}{\left(\pi \theta_{H M}^{\alpha}-\pi \theta_{L M}^{\alpha}+\lambda_{L+1}\right)\left(\lambda_{L}+\beta_{L N} \theta_{N}^{\alpha}\right)},
\end{gathered}
$$

and

$$
\begin{aligned}
c_{k M} \theta_{k M}^{1-\alpha} & =\frac{\left(1-\beta_{k M}\right) \mu_{k M} y-\beta_{k M} c_{k M} \theta_{k M}}{(r+s)} \\
& -\frac{\theta_{N}^{\alpha}\left(1-\beta_{k M}\right) \beta_{k N} \mu_{k N} y}{(r+s)\left(\lambda_{k}+\beta_{k N} \theta_{N}^{\alpha}\right)}
\end{aligned}
$$

where

$$
\lambda_{k}=r+s+\theta_{k M}^{\alpha}
$$

and

$$
\lambda_{k+1}=\theta_{k M}^{\alpha}+s+\theta_{N}^{\alpha} .
$$

We refer to (26) as $F_{2}$ for $k=L$ and $F_{3}$ for $k=H$.

Denote the Jacobian matrix as $J$, with determinant DetJ. Since the derivatives $F_{2, \theta_{H M}}$ and $F_{3, \theta_{L M}}$ equal zero, this determinant simplifies to

$$
\text { Det } J=F_{1, \theta_{N}} F_{2, \theta_{L M}} F_{3, \theta_{H M}}-F_{1, \theta_{L M}} F_{2, \theta_{N}} F_{3, \theta_{H M}}-F_{1, \theta_{H M}} F_{2, \theta_{L M}} F_{3, \theta_{N}} .
$$

Given the large number of parameters of the model, there are many sets of sufficiency conditions that ensure that this determinant has the required non-zero sign. In what follows, we are content with obtaining sufficiency conditions for the determinant to be strictly positive, and for the case where the bargaining power across worker occupations and skill levels are the same: $\beta_{L M}=\beta_{H M}=\beta_{L N}=\beta_{H N} \equiv \beta$. 
Lemma 1 Assuming $\beta_{L M}=\beta_{H M}=\beta_{L N}=\beta_{H N} \equiv \beta$, Det $J>0$ when the following conditions hold.

$$
\begin{gathered}
\pi>1 / 2 \\
\pi\left(p_{H M}-p_{L M}\right)<\min \left[(1-\beta) p_{N}, \beta p_{N}\right] \\
\mu_{H N}<\frac{2-\pi}{1-\pi} \\
c_{L M} \theta_{L M}^{1-\alpha}(1-\alpha)+\frac{c_{L M} \theta_{L M} \beta}{r+s}<\frac{\theta_{N}^{\alpha} \theta_{L M}^{\alpha} y \beta \alpha(1-\beta)}{(r+s)\left(\lambda_{L}+\theta_{N}^{\alpha} \beta\right)^{2}} \\
c_{H M} \theta_{H M}^{1-\alpha}(1-\alpha)+\frac{c_{H M} \theta_{H M} \beta}{r+s}<\frac{\theta_{N}^{\alpha} \theta_{H M}^{\alpha} \mu_{H N} y \beta \alpha(1-\beta)}{(r+s)\left(\lambda_{H}+\theta_{N}^{\alpha} \beta\right)^{2}} .
\end{gathered}
$$

Proof. A sufficient condition for Det $J>0$ is that $F_{1, \theta_{N}} F_{2, \theta_{L M}} F_{3, \theta_{H M}}>0$, $F_{1, \theta_{L M}} F_{2, \theta_{N}} F_{3, \theta_{H M}}<0$, and $F_{1, \theta_{H M}} F_{2, \theta_{L M}} F_{3, \theta_{N}}<0$.

A sufficient condition for the first term in (27) to be strictly positive is $F_{1, \theta_{N}}>0$ and $F_{2, \theta_{L M}}<0$ and $F_{3, \theta_{H M}}<0$. It can be shown that $F_{1, \theta_{N}}>0$ when (29) holds. The second condition holds iff (31) holds. Moreover, we have $F_{3, \theta_{H M}}<0$ iff (32) holds.

The second term in (27) is strictly negative when $F_{1, \theta_{L M}} F_{2, \theta_{N}} F_{3, \theta_{H M}}<0$. It can be shown that $F_{2, \theta_{N}}>0$ always, and, as stated above, $F_{3, \theta_{H M}}<0$ because of (32). Thus the second term in (27) is strictly negative when $F_{1, \theta_{L M}}>0$; the latter holds when (28) and (30) hold (again, full details are available from the authors upon request).

The last term in $(27)$ is strictly negative when $F_{1, \theta_{H} M} F_{2, \theta_{L M}} F_{3, \theta_{N}}<0$. It can be shown that we always have $F_{3, \theta_{N}}>0$ and that we have $F_{1, \theta_{H M}}>0$ when (28) holds. Finally, $F_{2, \theta_{L M}}<0$ iff (31).

\subsection{The Management Premium}

Here we prove the following: For each fixed $\beta_{k N}$ there is for type $k$ a unique critical value of $\beta_{k M}$, denoted $\beta_{k M}^{*}$, where $0<\beta_{k M}^{*}<\beta_{k N}<1$, and such that the management premium is strictly negative for all $\beta_{k M}$ satisfying $0 \leq \beta_{k M}<\beta_{k M}^{*}$ and strictly positive for all $\beta_{k M}>\beta_{k M}^{*}$. The proof is as follows.

We consider the management premium as a function of the bargaining powers $\beta_{k M}$ and $\beta_{k N}$, and so introduce the notation $w_{k M}-w_{k N} \equiv$ $f_{k}\left(\beta_{k M}, \beta_{k N}\right)$. The following lemma states that a sufficient condition for 
the management premium to be positive for type $k$ is that type $k$ has greater bargaining power in the management than in the non-management sector.

Lemma $2 f\left(\beta_{k M}, \beta_{k N}\right)>0$ whenever $\beta_{k M}>\beta_{k N}$.

Proof. The wage $w_{k M}$ can be written as

$w_{k M}=\frac{y}{A}\left[\left(r+s+p_{k M}+\beta_{k M} p_{N}\right) \beta_{k M} \mu_{k M}+\beta_{k N}\left(1-\beta_{k M}\right) \mu_{k N} p_{N}\right]+\beta_{k M} c_{k M} \theta_{k M}$,

where $A=r+s+p_{k M}+\beta_{k N} p_{N}$. The management premium can then be written as

$$
\begin{aligned}
& \left.\frac{y}{A}\left[\left(r+s+p_{k M}+\beta_{k M} p_{N}\right) \beta_{k M} \mu_{k M}+\beta_{k N}\left(1-\beta_{k M}\right) \mu_{k N} p_{N}-\beta_{k N}\left(r+s+p_{k M}+p_{N}\right) \mu_{k N}\right)\right] \\
& +\beta_{k M} c_{k M} \theta_{k M} .
\end{aligned}
$$

A sufficient condition for this to be strictly positive is that the expression inside the square bracket is strictly positive. Writing all the terms inside the square bracket out and simplifying yields

$$
\left(r+s+p_{k M}\right) \mu_{k N}\left(\beta_{k M}-\beta_{k N}\right) .
$$

This is strictly positive iff $\beta_{k M}>\beta_{k N}$.

We next consider the boundary of the parameter space, where $\beta_{k M}=0$.

Lemma $3 f\left(0, \beta_{k N}\right)<0$ for all $\beta_{K N}$.

Proof. Setting $\beta_{k M}=0$ in the expression above for $w_{k M}-w_{k N}$ and simplifying, the condition $w_{k M}<w_{k N}$ is equivalent to $0<\beta_{k N}\left(r+s+p_{k M}\right)$, which holds.

Lemma $4 f\left(\beta_{k M}, \beta_{k N}\right)$ is strictly increasing in $\beta_{k M}$ for any $\beta_{k N}$.

Proof. Since $w_{k M}$ but not $w_{k N}$ depends on $\beta_{k M}$, we need to prove that $w_{k M}$ is increasing in $\beta_{k M}$. First, $w_{k M}$ can be written as

$$
A+\beta_{k M} B
$$

where $A=\beta_{k N} \mu_{k N} p_{n} y /\left(r+s+p_{k M}+\beta_{k N} p_{N}\right)$, and

$$
B=\left(r+s+p_{k M}+\beta_{k N} p_{N}\right)\left[c_{k M} \theta_{k M}+\mu_{k M} y-\beta_{k N} \mu_{k N} p_{N} y\right]
$$


This expression can be further rewritten as

$\left(r+s+p_{k M}+\beta_{k N} p_{N}\right) c_{k M} \theta_{k M}+\left(r+s+p_{k M}\right) \mu_{k M} y+\beta_{k N} p_{N} \mu_{k M} y-\beta_{k N} p_{N} \mu_{k N} y$

The first three terms are positive, and the same holds for the two last since, by assumption, $\mu_{k M} \geq \mu_{k N}$.

These lemmas imply the existence, for any fixed $\beta_{k N}$, of a unique value of $\beta_{k M}$, denoted $\beta_{k M}^{*}$, such that $f\left(\beta_{k M}^{*}, \beta_{k N}\right)=0$. Moreover, due to Lemma 2 and 4 , we have $0<\beta_{k M}^{*}<\beta_{k N}<1$, and $f\left(\beta_{k M}, \beta_{k N}\right)<0$ for all $0 \leq \beta_{k M}<$ $\beta_{k M}^{*}$, and $f\left(\beta_{k M}, \beta_{k N}\right)>0$ for all $\beta_{k M}>\beta_{k M}^{*}$.

\subsection{Comparative Statics with Respect to $\pi$}

\subsubsection{Comparative Statics with Respect to the Steady State Prob- abilities}

We compute

$$
\begin{gathered}
F_{1, \pi}=\frac{y}{\left(\pi \theta_{H M}^{\alpha}+s+\theta_{N}^{\alpha}+(1-\pi) \theta^{\alpha}\right)^{2}} \\
\times\left(\frac{\left(\pi \theta_{H M}^{\alpha}+s+\theta_{N}^{\alpha}+\theta_{L M}^{\alpha}\right)\left(s+\theta_{N}^{\alpha}+\theta_{H M}^{\alpha}\right)(-1+\beta)}{r+s+\theta_{L M}^{\alpha}+\theta_{N}^{\alpha} \beta}\right. \\
\left.-\frac{\left(\pi \theta^{\alpha}+s+\theta_{N}^{\alpha}\right)\left(s+\theta N^{\alpha}+\theta_{L M}^{\alpha}\right)(-1+\beta) \mu_{H N}}{\left.r+s+\theta_{H M}^{\alpha}+\theta_{N}^{\alpha} \beta\right)}\right)>0
\end{gathered}
$$

where the sign follows if we assume that the conditions for existence are satisfied and that

$$
\mu_{H N}>\frac{p_{H M}}{p_{L M}} .
$$

It then follows, using Cramer's rule, that

$$
\frac{\partial \theta_{N}}{\partial \pi}<0, \frac{\partial \theta_{L M}}{\partial \pi}<0, \frac{\partial \theta_{H M}}{\partial \pi}<0
$$

\subsubsection{Comparative Statics with Respect to the Steady State Em- ployment Shares}

Considering next the effect of a change of $\pi$ on the steady state employment shares, we get 


$$
\frac{\partial i_{L N}}{\partial \pi}=\frac{s p_{N}}{\left(s+p_{N}+p_{L M}\right)\left(s+p_{L M}\right)}+\frac{s \pi}{\left(s+p_{N}+p_{L M}\right)^{2}} \frac{\partial p_{N}}{\partial \pi} .
$$

It can be shown that $\frac{\partial i_{L N}}{\partial \pi}>0$ if $1>\left|\varepsilon_{\pi, \theta_{N}}\right|$. (Details are available from the authors upon request.) Similarly, we can compute

$$
\begin{gathered}
\frac{\partial i_{H N}}{\partial \pi}=-\frac{s p_{N}}{\left(s+p_{N}+p_{H M}\right)\left(s+p_{H M}\right)}+\frac{s(1-\pi)\left(s+p_{H M}\right)^{2}}{\left(s+p_{N}+p_{H M}\right) 2\left(s+p_{H M}\right)^{2}} \frac{\partial p_{N}}{\partial \pi} \\
-\frac{s \pi p_{N}\left(2 s+2 p_{H M}+p_{N}\right)}{\left(s+p_{N}+p_{H M}\right)^{2}\left(s+p_{H M}\right)^{2}} \frac{\partial p_{H M}}{\partial \pi} .
\end{gathered}
$$

Sufficient conditions for this derivative to be negative are $s>p_{H M}$ and $1>\left|\varepsilon_{\pi, \theta_{H M}}\right|$. Moreover,

$$
\frac{\partial i_{L M}}{\partial \pi}=\frac{p_{L M}}{s+p_{L M}}+\frac{s \pi}{\left(s+p_{L M}\right)^{2}} \frac{\partial p_{L M}}{\partial \pi}
$$

is positive if $1>\left|\varepsilon_{\pi, \theta_{H M}}\right|$.

$$
\frac{\partial i_{H M}}{\partial \pi}=-\frac{p_{H M}}{s+p_{H M}}+\frac{s \pi}{\left(s+p_{H M}\right)^{2}} \frac{\partial p_{H M}}{\partial \pi}<0 .
$$

\subsubsection{Comparative Statics with Respect to Wages}

We obtain

$$
\begin{gathered}
\frac{\partial w_{k N}}{\partial \pi}=\frac{\beta(1-\beta) \mu_{k N} y\left(r+s+p_{k M}\right)}{\left(r+s+p_{k M}+\beta p_{k M}\right)^{2}} \frac{\partial p_{N}}{\partial \pi} \\
-\frac{p_{N} \beta(1-\beta) \mu_{k N} y}{\left(r+s+p_{k M}+\beta p_{k M}\right)^{2}} \frac{\partial p_{k M}}{\partial \pi},
\end{gathered}
$$

and

$$
\begin{gathered}
\frac{\partial w_{k M}}{\partial \pi}=\frac{(1-\beta) y\left(r+s+p_{k M}\right)}{\left(r+s+p_{k M}+\beta p_{k M}\right)^{2}} \frac{\partial p_{N}}{\partial \pi} \\
-\frac{p_{N}(1-\beta) y}{\left(r+s+p_{k M}+p_{k M}\right)^{2}} \frac{\partial p_{k M}}{\partial \pi} \\
+\beta_{k M} \frac{\partial \theta_{k M}}{\partial \pi} .
\end{gathered}
$$

If $\left|\varepsilon_{\pi, \theta_{N}}\right|>\left|\varepsilon_{\pi, \theta_{k M}}\right|$, we obtain the following inequalities: 


$$
\frac{\partial w_{L N}}{\partial \pi}<0, \frac{\partial w_{H N}}{\partial \pi}<0, \frac{\partial w_{L M}}{\partial \pi}<0, \frac{\partial w_{H M}}{\partial \pi}<0 .
$$

Furthermore, we see that

$$
\frac{\partial w_{L M}}{\partial \pi}=\frac{1}{\beta} \frac{\partial w_{L N}}{\partial \pi}+\beta c_{K M} \frac{\partial \theta_{k M}}{\partial \pi} .
$$

This means that wages in the management sector for workers of any skill level tend to fall faster with $\pi$ than wages in the non-management sector. This completes the proof. 


\section{FIGURES AND TABLES}

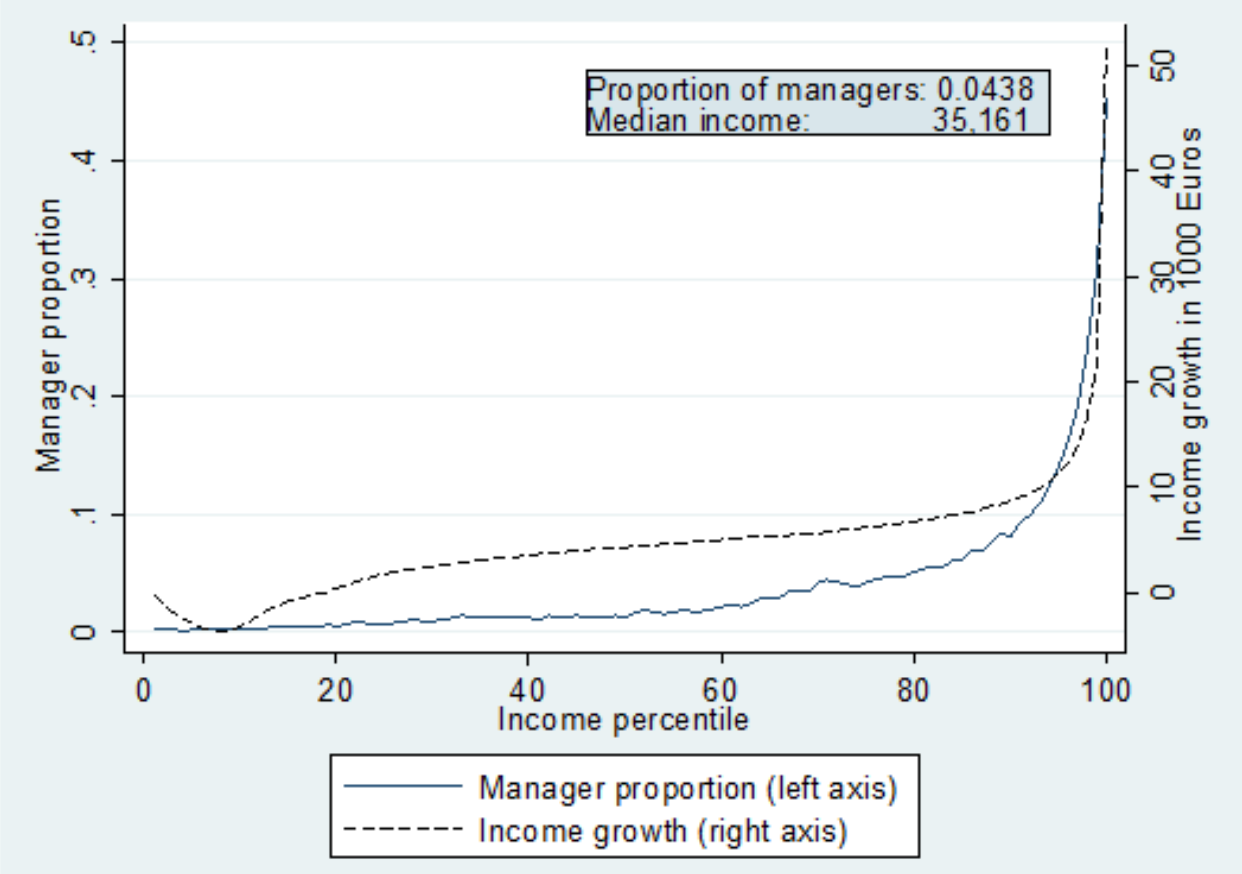

Figure 1. The location of managers and income growth by income percentile. 


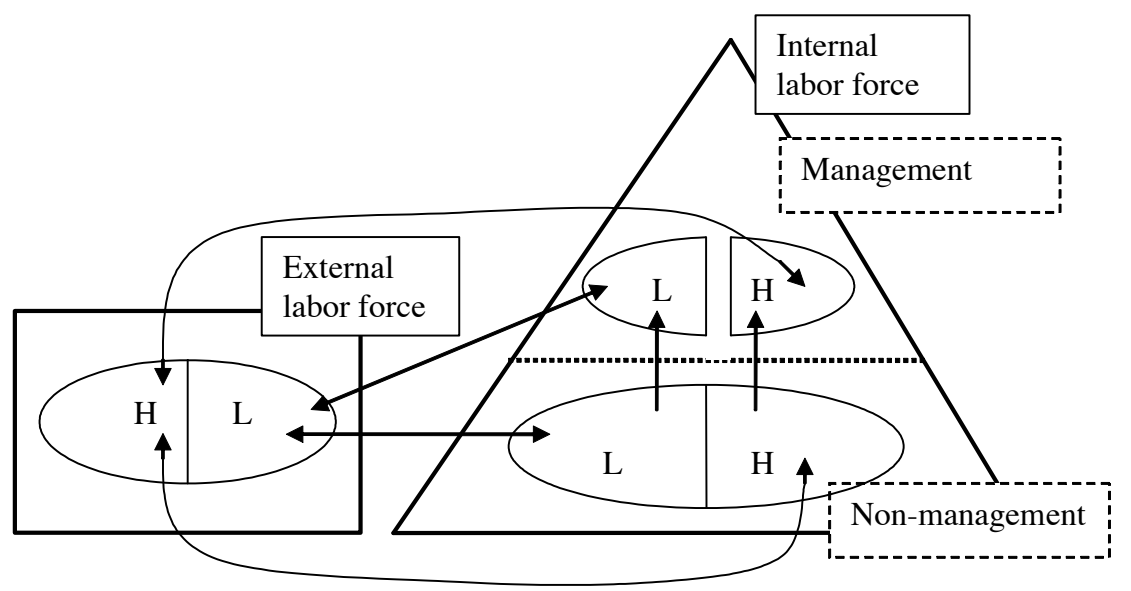

Figure 2. Flow diagram. 


\begin{tabular}{|c|c|c|c|}
\hline & 1992 & 2007 & $\begin{array}{c}\text { Change between } \\
1992 \text { and } 2007 \\
\end{array}$ \\
\hline $\begin{array}{l}\text { Employment } \\
\text { Less-educated } \\
\text { Non-management }\end{array}$ & 0.867 & 0.795 & $-8.3 \%$ \\
\hline $\begin{array}{l}\text { Highly-educated } \\
\text { Non-management }\end{array}$ & 0.082 & 0.165 & $101.2 \%$ \\
\hline $\begin{array}{l}\text { Less-educated } \\
\text { management }\end{array}$ & 0.040 & 0.025 & $-37.5 \%$ \\
\hline $\begin{array}{l}\text { Highly-educated } \\
\text { management }\end{array}$ & 0.011 & 0.014 & $27.2 \%$ \\
\hline $\begin{array}{l}\text { Real income* } \\
\text { Less-educated } \\
\text { Non-management }\end{array}$ & $\begin{array}{c}29,661 \\
(13,709)\end{array}$ & $\begin{array}{c}32,663 \\
(16,861)\end{array}$ & $10.1 \%$ \\
\hline $\begin{array}{l}\text { Highly-educated } \\
\text { Non-management }\end{array}$ & $\begin{array}{c}48,318 \\
(24,055)\end{array}$ & $\begin{array}{c}49,341 \\
(31,944)\end{array}$ & $2.1 \%$ \\
\hline $\begin{array}{l}\text { Less-educated } \\
\text { management }\end{array}$ & $\begin{array}{c}47,328 \\
(31,332)\end{array}$ & $\begin{array}{c}61,922 \\
(39,006)\end{array}$ & $30.8 \%$ \\
\hline $\begin{array}{l}\text { Highly-educated } \\
\text { management }\end{array}$ & $\begin{array}{c}73,838 \\
(42,531)\end{array}$ & $\begin{array}{c}94,057 \\
(75,279)\end{array}$ & $27.4 \%$ \\
\hline Average real income & $\begin{array}{c}32,391 \\
(18,037)\end{array}$ & $\begin{array}{c}37,020 \\
(25,940)\end{array}$ & $14.3 \%$ \\
\hline Gini coefficient & 0.42 & 0.57 & 0.15 \\
\hline
\end{tabular}

*Income is measured as yearly real income in Euros, with 2000 as the base year. Observations: 18,406,618.

Table 1. Changes in relative income and employment proportions between 1992 and 2007. 


\begin{tabular}{|c|c|c|c|c|c|}
\hline & \multirow{2}{*}{$\begin{array}{c}\text { SD of log } \\
\text { wages }\end{array}$} & \multicolumn{3}{|c|}{ Percentiles of log income distribution } & \multirow{2}{*}{$\begin{array}{c}\text { Gini } \\
\text { coefficient }\end{array}$} \\
\hline & & $90-10$ & $90-50$ & $50-10$ & \\
\hline 1992 & 0.65 & 1.42 & 0.49 & 0.92 & 0.42 \\
\hline 2007 & 0.80 & 1.88 & 0.52 & 1.36 & 0.57 \\
\hline
\end{tabular}

Table 2. Measures of income inequality in Denmark, 1992 and 2007. 


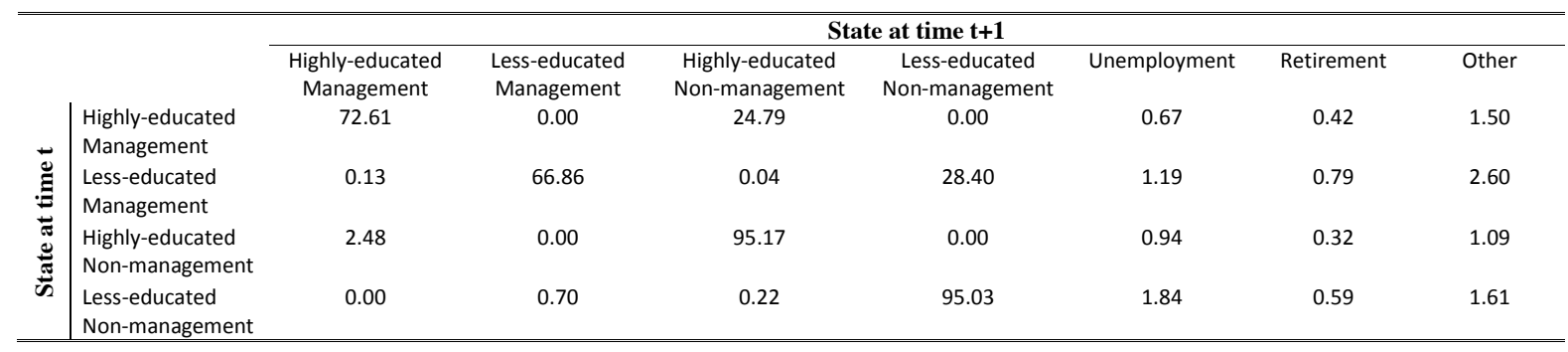

Table 3. Employment transition matrix. 


\begin{tabular}{|c|c|c|c|c|c|c|c|}
\hline & $\begin{array}{l}\text { Predicted Gini } \\
\text { coefficient }\end{array}$ & $\begin{array}{l}\text { Management } \\
\text { premium } \\
(\gamma)\end{array}$ & $\begin{array}{l}\text { Management } \\
\text { composition }\end{array}$ & $\begin{array}{l}\text { Education } \\
\text { premium } \\
\text { (n) }\end{array}$ & $\begin{array}{l}\text { Education } \\
\text { composition }\end{array}$ & $\begin{array}{l}\text { Controls } \\
\text { "prices" } \\
(\beta)\end{array}$ & $\begin{array}{l}\text { Controls } \\
\text { composition } \\
\text { (age and } \\
\text { experience) } \\
\end{array}$ \\
\hline Year 1992 & 0.225 & 1992 & 1992 & 1992 & 1992 & 1992 & 1992 \\
\hline Year 2007 & 0.295 & 2007 & 2007 & 2007 & 2007 & 2007 & 2007 \\
\hline The effect of skill-upgrading & 0.201 & 1992 & 1992 & 1992 & $2007^{*}$ & 1992 & 1992 \\
\hline $\begin{array}{l}\text { The effect of the rising } \\
\text { management premium }\end{array}$ & 0.297 & 2007 & 1992 & 1992 & 1992 & 1992 & 1992 \\
\hline $\begin{array}{l}\text { The combined effect of skill- } \\
\text { upgrading and the rising } \\
\text { management premium }\end{array}$ & 0.272 & 2007 & 1992 & 1992 & $2007^{*}$ & 1992 & 1992 \\
\hline
\end{tabular}

Table 4. Simulation of the importance of skill-upgrading and the rising management premium for income inequality. 